\title{
Bibliotecas Científicas
}

\author{
J. A. MARTINHO SIMÕES
}

0 Português lê pouquíssimo. Basta andar de autocarro, de comboio, esperar num consultório médico, para ver que as pessoas preferem mirar 0 vizinho, a paisagem ou o vácuo a ler um livro ou mesmo o jornal. É certo que os livros são caros, mas isso não serve de desculpa. Embora a posse dos livros seja essencial para os viciados como eu, há sempre a possibilidade de os pedir emprestados a amigos ou a uma biblioteca. Onde começa o problema? $\mathrm{Na}$ escola. Em países como o Canadá ou o Reino Unido, as bibliotecas surgem na escola primária, e as crianças são estimuladas não apenas a fazerem pesquisas bibliográficas para os seus trabalhos, como a participarem na organização (ficheiro, controle de empréstimos, etc.) da própria biblioteca. É a idade própria para injectar o vírus.

0 Cientista Português lê, também, muito pouco. Basta visitar uma das nossas bibliotecas universitárias, normalmente sub-dimensionadas para o número de potenciais utilizadores, e verificar que sobeja espaço para leitores! É certo que muitas dessas bibliotecas são desconfortáveis, funcionam em horários inadmissiveis (algumas até fecham para almoço...), e estão organizadas em função do bibliotecário e não do leitor. Porisso, há quem prefira (como eu) pactuar, até certo ponto, com a praga das fotocópias e, o mais rapidamente possível, regressar ao remanso do gabinete. Mas, mesmo contando com os leitores xerox, não tenho dúvidas em afirmar que muitos cientistas portugueses pouco vão sabendo do que se passa em outros laboratórios que não o seu...É claro que a necessidade da pesquisa bibliográfica acaba por surgir, por exemplo, quando se escreve um artigo. É esta a altura de pôr as leituras em dia. No entanto, a simples atitude de ir à biblioteca, gastar uns minutos ou umas horas a ler ou meramente a folhear umas revistas, é rara entre nós.

0 conhecimento profundo do trabalho publicado por outros é essencial para a qualidade do nosso próprio trabalho. Isto é tão óbvio que quase embaraça escrevê-lo. Masfaço-o porque pior que a irrecuperável fobia de leitura de alguns dos nossos cientistas é a leviandade com que muitos dos nossos estudantes pós-graduados encaram a consulta regular de artigos científicos. Por mais absorvente que seja o trabalho do laboratório, há sempre um furo para ver o que se passa noutros lados.

Vem tudo isto a propósito de algumas notícias dispersas sobre a possivel reorganização das bibliotecas científicas portuguesas. Pelo que se disse acima, até parece não valer a pena... Creio, no entanto, que esta conclusão é errada. Primeiro porque a má qualidade média das nossas bibliotecas tem alguma responsabilidade na falta de leitores mais assíduos. Segundo porque, mesmo que as melhorias não contribuíssem para aumentar o número destes, é preciso ter em conta que realizar hoje, em Portugal, uma pesquisa bibliográfica séria é tarefa impossível, pelo menos na área da Química. Dou apenas um exemplo. A Biblioteca da Química da Universidade de Coimbra era excelente (pelo menos no nosso pobre panorama): dispunha de colecções completas de grande parte das revistas essenciais para uma pesquisa bibliográfica minimamente exaustiva. Infelizmente, creio que em 1983 ou 84 , por falta de verba, foi forçada a desistir das assinaturas de muitos títulos, em particular das colecções oriundas da ex-URSS. E claro que os químicos portugueses que agora necessitam de artigos dessas revistas, pedem a amigos no estrangeiro ou pagam centenas de escudos por cópia de cada página-sem falar no tempo de espera. Mas se esta infeliz decisão pode ser atribuída ao poder político, que dizer duma outra, mais recente, da responsabilidade de um cientista, que resolveu pagar verbas em dívida à EDP em vez de renovar assinaturas de revistas? (A história acabou em bem: o dinheiro lá apareceu e, ao fim de um ano, as colecções foram repostas).

Manter várias bibliotecas científicas de grande qualidade é extremamente dispendioso. Mas é necessário compreender que a existência dessas bibliotecas é crucial para o nosso desenvolvimento. Além de que, como dizia uma pessoa muito respeitada (mas nem sempre ouvida...) da nossa comunidade científica, não se compreende que uma universidade de terceira nos EUA tenha uma biblioteca muito melhor que qualquer uma das nossas grandes universidades públicas. Quais são os limites do terceiro mundismo?

É evidente, também, que se podem e devem racionalizar gastos. Este é, aliás, precisamente 0 assunto que me levou a escrever o presente comentário, que, sublinho, apenas reflecte a minha condição de utilizador frequente de muitas bibliotecas nacionais e estrangeiras. É como que um desabafo de um leitor típico (?) de literatura científica. Haverá, no entanto, vozes mais importantes?

Vou à biblioteca normalmente uma vez por semana. Folheio normalmente 15-20 títulos (a minha área científica tem uma grande actividade) e fotocopio, para ir lendo, os artigos que me interessam mais (tomo nota ou copio a primeira página dos que penso que me podem vir a ser úteis). No final de cada ano faço uma leitura do Chemical Abstracts Selects da minha área, para verificar se me escapou alguma coisa importante. Este procedimento é, mais revista menos revista, o seguido por algumas das pessoas que conheço e que mantêm actividade científica constante. Convém igualmente referir que cerca de $95 \%$ dos trabalhos que são relevantes para a minha actividade são publicados em apenas meia dúzia de revistas. É vulgar, no entanto, necessitar de uma revista que não existe em Portugal.

0 que seria necessário para melhorar significativamente o sistema?

1. ${ }^{\circ}$ Haver pelo menos uma biblioteca em Portugal que mantivesse uma colecção de títulos suficientemente grande para que se evitasse 0 recurso frequente a bibliotecas estrangeiras.

2. ${ }^{-}$Preservar nas bibliotecas universitárias as colecções mais importantes.

3. ${ }^{\circ}$ Aumentar a interacção entre as bibliotecas universitárias. 


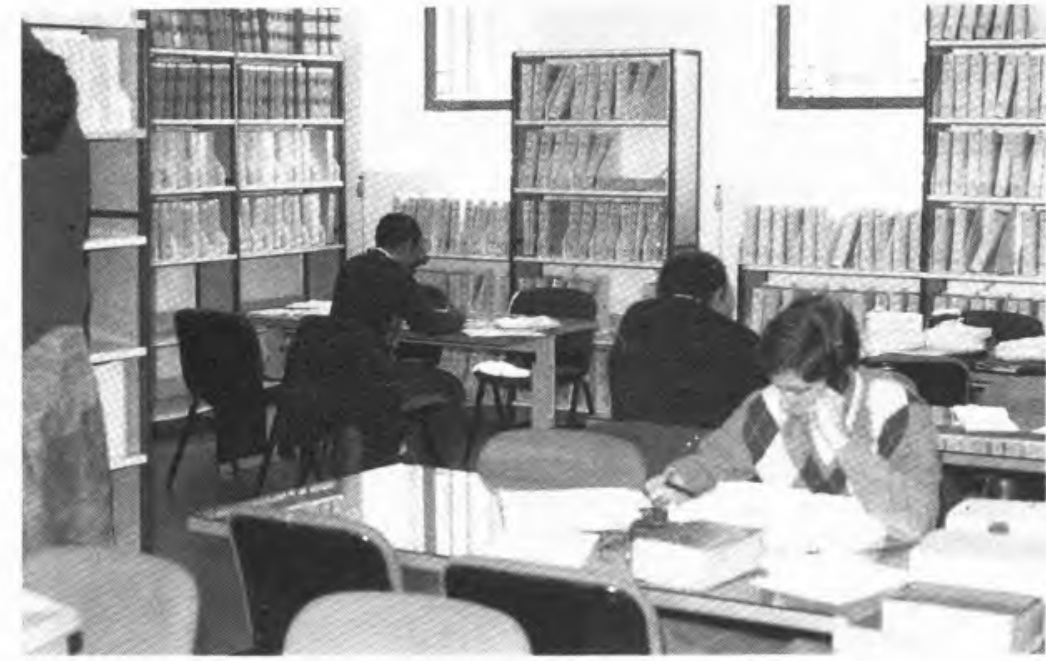

4. ${ }^{\circ}$ Alargar o período de funcionamento das bibliotecas (no mínimo das 8-21 horas, todos os dias).

5. ${ }^{\circ}$ Dotar as bibliotecas com equipamento moderno (reprodução em papel de documentos em microfilme, possibilidade de pesquisas em bases de dados bibliográficas e outras, etc.).

6. ${ }^{\circ}$ Organizar acções de reciclagem para bibliotecários e outro pessoal de apoio ao funcionamento das bibliotecas.

Desta "wish list", que não é exaustiva, vale a pena comentar cada ponto, excepto os dois últimos. Começando pelo primeiro, devo referir que há quem discorde do conceito de super-biblioteca, uma instituição onde se reuna "tudo", nomeadamente no que respeita às publicações científicas periódicas. Pela minha parte parece-me uma excelente ideia, desde que sejam cumpridos alguns pressupostos. Essa super-biblioteca teria necessariamente meios técnicos e humanos para assegurar que qualquer pedido de um artigo fosse satisfeito num prazo muito curto (máximo de 24-48 horas), ou fosse mesmo enviado por fax, se a urgência o justificasse. Teria que estar localizada num sítio de acesso fácil e 0 seu horário de funcionamento deveria ser bastante amplo. Finalmente, não deveria implicar o esvaziamento das bibliotecas universitárias.

Por motivos óbvios ficaria muito satisfeito se essa super-biblioteca estivesse localizada em Lisboa, mas devo dizer que daria todo 0 apoio à sua criação em qualquer outrolocal.É claro que a existência de uma só superbiblioteca, se bem que fosse um grande avanço, continuava a ser uma solução algo miserabilista. A dimensão de algumas das nossas universidades justifica a criação de várias dessas instituições. E é também evidente que no caso de existir uma pequena rede de super-bibliotecas deveria haver uma profunda interacção entre elas, de forma a garantir alguma complementaridade dos títulos mais exóticos.

Criadas essas super-bibliotecas, qual o papel das bibliotecas mais pequenas (aqui chamadas universitárias ou departamentais)? Referi atrás que a esmagadora maioria dos artigos do meu interesse imediato é publicada em meia dúzia de revistas (as quais é essencial ter à mão de semear - ponto 2). Assim, não teria qualquer dúvida em sacrificar algumas das colecções da biblioteca do meu departamento e cedê-las à super-biblioteca da minha área. Uma visita mensal bastaria para as consultar. Se, por outro lado, não existisse nenhuma super-biblioteca na minha região, o sistema poderia ser bastante racionalizado pelo aumento de interacção entre as bibliotecas universitárias (ponto 3), com vista a conseguir-se complementaridade de alguns títulos. Muitas colecções de interesse menos primário, que hoje existem em duplicado, ou triplicado (por vezes dentro do mesmo campus!), poderiam ser interrompidas e a verba ser utilizada para aquisição de livros e de assinaturas de revistas importantes que ninguém tem! Este tipo de interacção existe por exemplo nas bibliotecas de algumas universidades na região de Los Angeles. Em 24 horas, é possivel obter cópia de um artigo de uma revista existente noutro local.

Estou consciente que as ideias gerais que aponto são polémicas, em especial por parecerem implicar um certo esvaziamento das bibliotecas universitárias. Creio que expliquei com clareza que não é disso que se trata: apenas pretendo uma maior racionalização dos recursos bibliográficos ao dispôr da comunidade científica e, com o menor investimento possivel, ter pelo menos uma excelente biblioteca cientifica em Portugal. Mesmo sem super-biblioteca(s), creio que a interacção forte entre todo o sistema de bibliotecas universitárias conduziria rapidamente a melhorias substanciais, por exemplo aumentando o número total de títulos disponiveis - e este é um dos pontos vitais para todos nós.

Menos polémico, mas não menos importante, será o ponto 4 . Há uns anos, a biblioteca de um departamento de química de uma das nossas universidades tinha horário de funcionalismo público, embora esse mesmo departamento assegurasse aulas nocturnas a estudantes-trabalhadores! Presumo que este tipo de mentalidade (a biblioteca é para se mostrar às visitas-diurnas) ainda vigora em alguns locais, apesar de a solução ser simples e barata: basta arranjar um conjunto de estudantes, pagos como tarefeiros, e encarregá-los da "vigilância" da biblioteca, fora das horas de trabalho do pessoal permanente. Quando dei esta sugestão, há cerca de dez anos, houve alguma resistência e desconfiança, mas a solução vingou e hoje a biblioteca tem 12 horas de funcionamento ininterrupto. Mas não chega. Está-se ainda longe de uma solução satisfatória. Por exemplo, numa das universidades modelo dos EUA, 0 California Institute of Technology, a biblioteca nunca encerra. E os estudantes são em menor número que na mais pequena das nossas universidades...

Com ou sem injecções de dinheiro, é urgente que as nossas bibliotecas científicas sejam reorganizadas. A tarefa não parece particularmente complexa, desde que haja um pouco de boa vontade de todos e alguma dose de bom senso. E antes de se tomarem decisões, ouçam-se os bibliotecários, ouçam-se os reitores, os directores de faculdades, os presidentes de departamento, mas tenha-se em devido respeito a opinião de todos os que de facto necessitam de literatura científica para a sua actividade diária. 